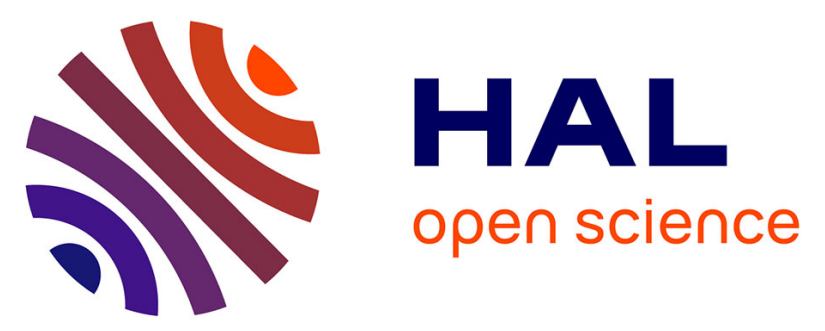

\title{
CSF concentration of cefotaxime in adult patients with pneumococcal meningitis: a multicentre retrospective study
}

Paul Le Turnier, Najoua El Helali, Romain Guilhaumou, Benoit Pilmis, Matthieu Revest, Lionel Velly, Anne-Gaëlle Leroy, Xavier Duval, Florian

Lemaitre, Matthieu Grégoire, et al.

\section{To cite this version:}

Paul Le Turnier, Najoua El Helali, Romain Guilhaumou, Benoit Pilmis, Matthieu Revest, et al.. CSF concentration of cefotaxime in adult patients with pneumococcal meningitis: a multicentre retrospective study. Journal of Antimicrobial Chemotherapy, 2021, 76 (9), p. 2352-2355. 10.1093/jac/dkab191 . hal-03281931

\section{HAL Id: hal-03281931 \\ https://hal.science/hal-03281931}

Submitted on 12 Jul 2021

HAL is a multi-disciplinary open access archive for the deposit and dissemination of scientific research documents, whether they are published or not. The documents may come from teaching and research institutions in France or abroad, or from public or private research centers.
L'archive ouverte pluridisciplinaire HAL, est destinée au dépôt et à la diffusion de documents scientifiques de niveau recherche, publiés ou non, émanant des établissements d'enseignement et de recherche français ou étrangers, des laboratoires publics ou privés. 
Title:

CSF concentration of cefotaxime in adult patients with pneumococcal meningitis: a multicentre retrospective study

\section{Authors}

8 Paul LE TURNIER ${ }^{1}$, Najoua EL HELALI ${ }^{2}$, Romain GUILHAUMOU ${ }^{3}$, Benoit PILMIS ${ }^{4}$, Matthieu

9 REVEST ${ }^{5}$, Lionel VELLY ${ }^{6}$, Anne-Gaëlle LEROY ${ }^{7}$, Xavier DUVAL $^{8}$, Florian LEMAITRE 9 , Matthieu 10 GREGOIRE $^{10}$ on behalf of the DIFCEFO study group $\dagger$

$11{ }^{1}$ Department of Infectious Diseases, Nantes University Hospital, Nantes, France - INSERM CIC 1413, 12 Nantes University Hospital, Nantes, France

$13{ }^{2}$ Plateforme de Dosages des Anti-infectieux, Groupe Hospitalier Paris Saint-Joseph, Paris, France

$14^{3}$ Aix Marseille Univ, Department of Clinical Pharmacology and Pharmacovigilance CIC-CPCET, 15 University Hospital Timone - Institut de neurosciences des systèmes, Inserm UMR 1106, Marseille, 16 France

$17{ }^{4}$ Equipe Mobile de Microbiologie Clinique, Groupe Hospitalier Paris Saint-Joseph, Paris, France 18 Institut Micalis UMR 1319, Université Paris-Saclay, INRAe, AgroParisTech, Châtenay Malabry, France

$19{ }^{5}$ Infectious Diseases and Intensive Care Unit, Rennes University Hospital, Rennes, France - University of 20 Rennes, Centre d'Investigation Clinique 1414, INSERM, Bacterial Regulatory RNAS and Medicine, 21 Unité Mixte de Recherche 1230, Rennes, France 
$22{ }^{6}$ Aix Marseille Univ, Department of Anaesthesiology and Critical Care Medicine, University Hospital 23 Timone - CNRS, INT, Inst Neurosci Timone, UMR7289, Marseille, France

$24{ }^{7}$ Department of Microbiology, Nantes University Hospital, Nantes, France

$25{ }^{8}$ Paris University, IAME, INSERM, Paris, France - Inserm Clinical Investigation Centre 1425, Paris,

26 France - Inserm, F-CRIN, Innovative Clinical Research Network in Vaccinology (I-REIVAC), Paris,

27 France

$28{ }^{9}$ Univ Rennes, CHU Rennes, Inserm, EHESP, Irset (Institut de recherche en santé, environnement et 29 travail), Rennes, France - UMR_S 1085, F- INSERM, Centre d'Investigation Clinique, CIC 1414, 30 Rennes, France

$31{ }^{10}$ Clinical Pharmacology Laboratory Department Nantes University Hospital, Nantes, France - UMR

32 INSERM 1235, The enteric nervous system in gut and brain disorders, University of Nantes, Nantes, 33 France

$34 \uparrow$ Members are listed in the Acknowledgements section

$35 *$ Corresponding author

36

\section{Corresponding author}

38 Paul Le Turnier. Address : Department of Infectious and Tropical diseases, Nantes University Hospital, 1

39 place Alexis Ricordeau 44093, Nantes, France. International phone number/fax : +332400833 47/+332

40400833 30. E-mail : paul.leturnier@gmail.com

\section{Running title}

43 Cefotaxime in adult pneumococcal meningitis CSF 
Background and objectives: Pneumococcal meningitis is a devastating disease that requires adequate meningeal antibiotic penetration to limit the mortality. Despite a large usage in this indication, data about

47 CSF concentration of cefotaxime during pneumococcal meningitis in adults are scarce. Therefore we aimed to describe the CSF concentration obtained after high-dose cefotaxime administration in adult patients treated for Streptococcus pneumoniae meningitis.

Patients and methods: In this multicentre, observational, retrospective study, cases of adult patients with S. pneumoniae meningitis hospitalized between January 2013 and October 2019 for whom cefotaxime

52 concentration was measured in CSF were reviewed.

53 Results: Cefotaxime concentration was analysed in 44 CSF samples collected among 31 patients... 54 Median (IQR) age was 61 years (52;69). Dexamethasone was administered in 27 subjects. Median (IQR) 55 cefotaxime daily dosage was $15 \mathrm{~g}(12 ; 19)$ corresponding to $200 \mathrm{mg} / \mathrm{kg}(150 ; 280)$. CSF samples were 56 collected 5 days after cefotaxime initiation roughly. Median (IQR, range) cefotaxime CSF concentration 57 was $10.3 \mathrm{mg} / \mathrm{L}(4.8 ; 19.3,1.2-43.4)$. Median (range) MIC of Streptococcus pneumoniae was $0.25 \mathrm{mg} / \mathrm{L}$ $58(0.008-1)(\mathrm{n}=22)$. The median (IQR, range) CSF/MIC ratio was $38(12 ; 146,4-1844)$. Twenty-five CSF 59 concentrations $(81 \%)$ were above 10 times the MIC. Cefotaxime was discontinued in 2 patients for toxicity. In-hospital mortality rate was $29 \%$.

61 Conclusions: Adult patients with pneumococcal meningitis treated with high dose of cefotaxime (200 $62 \mathrm{mg} / \mathrm{kg} / \mathrm{day}$ ) had elevated CSF concentrations with satisfying pharmacokinetics/pharmacodynamics 63 parameters and tolerability profile. This study brings reassuring pharmacological data regarding the use of 64 high dose cefotaxime monotherapy for treating pneumococcal meningitis with susceptible strains to 65 cefotaxime. 
Streptococcus pneumoniae meningitis is a devastating disease with the highest morbidity and mortality

70

71

72

73

74

75

76

77

78

79

80

81

82

83

84

85

86

87

88

89

90

91 among community-acquired bacterial meningitis. ${ }^{1}$ Cefotaxime is a third-generation cephalosporin (3GC) widely recommended for the treatment of pneumococcal meningitis. French guidelines for management of acute bacterial meningitis recommend dosage of cefotaxime to be weight-based without any upper limit whereas international guidelines recommend a maximum daily dosage of 12 g. ${ }^{2-4}$ The adequacy between antibiotic penetration in CSF and antibiotic susceptibility of Streptococcus pneumoniae is a cornerstone to achieve satisfying pharmacokinetics/pharmacodynamics (PK-PD) targets in this lethal disease. The increasing incidence of Streptococcus pneumoniae isolates with reduced susceptibility to 3GC is therefore a matter of concern. ${ }^{5}$ Given these epidemiological changes, data about cefotaxime penetration in CSF might offer relevant information. ${ }^{6}$ However, very limited data exist about CSF penetration of cefotaxime when meningeal dose are used in adults treated for pneumococcal meningitis. We aimed to describe the CSF penetration of cefotaxime in adult patients treated for S. pneumoniae meningitis.

\section{Patients and methods}

We conducted a multicentre, observational, retrospective study. Adult patients hospitalized between January 2013 and October 2019 for whom cefotaxime concentration was measured in CSF as part of the routine care were identified in the participating centres and among the participants of the COMBAT cohort (NCT02916732). Among them, individuals treated for proven pneumococcal meningitis, with either positive CSF culture or CSF PCR assay for Streptococcus pneumoniae, were included. Medical charts were retrospectively reviewed to collect clinical, pharmacological and microbiological data. CSF parameters were reported at the time of cefotaxime concentration measurements in CSF. Concomitant cefotaxime plasma concentrations (same day) were collected when available. All CSF concentrations were measured within $48 \mathrm{~h}$ following CSF sampling and were systematically stored at $-80^{\circ} \mathrm{C}$ if they were 
92 not immediately performed. Antibiotic concentrations were measured in CSF and plasma using a liquid-

93 chromatography coupled with mass-spectrometry or diode-array detector validated assay. Limit of

94 quantitation was $1 \mathrm{mg} / \mathrm{L}$. A steady-state plasma concentration was defined by a cefotaxime concentration

95 measured at least 24 hours after treatment initiation. Plasma concentrations were considered as trough

96 levels when continuous infusion was used or when discontinued infusion was used and plasma samples

97 collected just before infusion.

98 Cefotaxime MIC were determined using an Etest strips or Vitek 2 automated system (bioMérieux,

99 France) depending on usual practices of the different centres and according to the European Committee 100 on Antimicrobial Susceptibility Testing (EUCAST) guidelines. The study received ethical approval from

101 the Research Ethics Committee on Infectious and Tropical Diseases (CERMIT2019-0706,

102 IRB00011642). Participants were informed of the study in accordance with French legal standards.

103 A Wilcoxon rank sum test was used to compare the cefotaxime CSF levels between patients with and 104 without dexamethasone with a significance level of 0.05 .

105 Results

106

Study population

107 In total, 31 individuals were included. Their characteristics are reported in Table 1. Median (IQR) age 108 was 61 years (52;69). Dexamethasone was administered in 27 subjects (87 \%). Median (IQR) cefotaxime 109 daily dosage was $15 \mathrm{~g}(12 ; 19)$ corresponding to $200 \mathrm{mg} / \mathrm{kg}(150 ; 280)$. Sixteen out of 28 patients received 110 cefotaxime by continuous intravenous infusion (3 missing data).

111 Pharmacokinetics-pharmacodynamics analysis

112 Forty-four CSF concentrations (from 1 to 4 per patient) and 28 plasma concentrations (from 0 to 4 per 113 patient) were measured. The median (IQR) time between cefotaxime initiation and CSF sampling was 114121 hours (78-194), all above 24 hours (2 missing data). For patients who did not receive continuous 115 infusion, the median (IQR) time between cefotaxime preceding infusion and CSF sampling was 3.3 (1.5- 
117 Median (IQR) plasma concentration was $60.5 \mathrm{mg} / \mathrm{L}$ (31.3-81.7). Plasma concentrations were trough levels 118 in 75\% (21/28) of patients. For paired CSF and plasma cefotaxime measurements ( $\mathrm{n}=28$ paired samples), 119 the median (IQR) calculated CSF/plasma ratio was $21.6 \%(8.6-28.5)$. The cefotaxime MIC of $S$. 120 pneumoniae was reported for $22(71 \%)$ subjects. Median (IQR, range) MIC was $0.25 \mathrm{mg} / \mathrm{L}(0.036 ; 0.5$, $1210.008-1)$. Based on the cefotaxime MIC of each patient's pneumococcal strain the median (IQR, range) 122 CSF/MIC ratio was 38 (12-146, 4-1844) (n=31 CSF samples). Twenty-five CSF concentrations (81\%) 123 were above 10 times the corresponding MIC. CSF cefotaxime levels did not differ between 124 dexamethasone- and non-dexamethasone-treated patients $(\mathrm{p}=0.59)$. Considering the weight-based daily 125 dosage and the associated CSF concentration, 6 patients received less than $150 \mathrm{mg} / \mathrm{kg} / \mathrm{day}$ ( $\mathrm{n}=9$ samples), 1266 between 150 and $199 \mathrm{mg} / \mathrm{kg} /$ day ( $\mathrm{n}=8$ samples), 11 between 200 and $280 \mathrm{mg} / \mathrm{kg} / \mathrm{day}(\mathrm{n}=13 \mathrm{samples}$ ), 6 127 above $280 \mathrm{mg} / \mathrm{kg} /$ day ( $\mathrm{n}=10$ ) with a median (IQR) CSF concentration of $7.5 \mathrm{mg} / \mathrm{L}(1.2 ; 29.3), 10.3 \mathrm{mg} / \mathrm{L}$ 128 (2.2;15.4), $5.4 \mathrm{mg} / \mathrm{L}(1.6 ; 23.8)$, and $18.3 \mathrm{mg} / \mathrm{L}(3.0 ; 43.4)$ respectively (see Table 2).

\section{Clinical outcomes}

130 Cefotaxime was discontinued because of toxicity in 2 patients (8.0\%, 6 missing data). One with acute 131 kidney injury experienced a neurological degradation with electroencephalogram abnormalities while 132 having elevated cefotaxime concentrations in CSF $(19.3 \mathrm{mg} / \mathrm{L})$ and plasma $(254.9 \mathrm{mg} / \mathrm{L})$. The details on 133 toxicity were not available for the other patient. In hospital mortality rate was $29 \%(9 / 31)$.

\section{Discussion}

135 Previous studies assessing CSF penetration of cefotaxime were mostly done in children and revealed 136 lower concentrations than in this study, ${ }^{7}$ or variable concentrations similarly to those observed here. ${ }^{8}$ 137 Interestingly, a previous PK/PD modelling study suggested that cefotaxime dosages of $4 \mathrm{~g} / 6 \mathrm{~h}$ would be 138 sufficient to achieve CSF levels above the MIC for $90 \%$ of time, even for pneumococcal strains with an 139 MIC of 2, which appear close to the results observed in the current study. ${ }^{9}$ 
The IDSA and the ESCMID guidelines for acute bacterial meningitis treatment in adults recommend a 141 cefotaxime daily dosage from 8 to $12 \mathrm{~g}$, in association with vancomycin or rifampicin when reduced 142 susceptibility to penicillin is suspected, which is the case in France. ${ }^{3,4}$ Meanwhile, French guidelines 143 promote a monotherapy of cefotaxime with a dose-weighted adjustment without any upper limit dosage 144 and recommend dosages based on cefotaxime susceptibility which range from $200 \mathrm{mg} / \mathrm{kg}$ when MIC is 145 below $0.5 \mathrm{mg} / \mathrm{L}$ (susceptible strain) to $300 \mathrm{mg} / \mathrm{kg}$ when $\mathrm{MIC}$ is between $0.5 \mathrm{mg} / \mathrm{L}$ and $2 \mathrm{mg} / \mathrm{L}$ 146 (intermediate strain) or unknown. ${ }^{2}$

147 Recently, Mizrahi and coll. reported a case of therapeutic failure in a patient with 3GC-intermediate 148 Streptococcus pneumoniae meningitis. ${ }^{10}$ After several days of ceftriaxone monotherapy the patient' state 149 worsened and repeated CSF culture revealed a 3GC-resistant Streptococcus pneumoniae isolate. This 150 resistance emergence possibly occurred due to insufficient exposition of antibiotics. ${ }^{11}$ Because a limited 151 exposition to antibiotics can lead to resistant strain selection, it appears necessary to target CSF concentrations far above the MIC although the optimal CSF/MIC ratio target remains uncertain. ${ }^{12}$

153 In France, the incidence of pneumococcal meningitis with decreased 3GC susceptibility reached its lowest 154 point in 2014 when $1.5 \%$ of strains were cefotaxime-intermediate and none resistant. Since then, this 155 proportion increased relatively with $6.6 \%$ in 2017 with rare resistant strains $(0.7 \%)$. ${ }^{13}$ The 156 pharmacological results of our study suggest that using high-dose cefotaxime $(200 \mathrm{mg} / \mathrm{kg}) \mathrm{seems}$ a 157 reasonable option to treat cefotaxime-susceptible strains. Notably, the highest CSF concentrations 158 observed in this cohort were found in patients receiving daily dosage above $280 \mathrm{mg} / \mathrm{kg}$ with a median of $15918 \mathrm{mg} / \mathrm{L}$ and were higher than previous reports in adults receiving meningeal dose of cefotaxime. ${ }^{14,15}$ 160 Those very high dosages corresponded approximately to the initial empirical dosage proposed by French 161 guidelines and could be sufficient to treat even cefotaxime-intermediate strains.

162 The global satisfying tolerability of cefotaxime despite the high doses used in the study population is in 163 accordance with previous reports of very high doses of other 3GC in patients treated for suspected CNS 164 infections. ${ }^{16}$ 
The limitations of our study include: i) the retrospective design, ii) a small sample size, which prevents to analyse the factors associated with CSF cefotaxime penetration and patients' outcomes, iii) some missing

167 data regarding the indication of CSF antibiotic dosing and the dosage of dexamethasone (although it is 168 likely that the recommended dosage of $10 \mathrm{mg} / \mathrm{q} 6 \mathrm{~h}$ was administered), iv) a possible selection bias because 169 repeated CSF analysis is not systematically recommended but only in case of elevated MIC or 170 unfavourable outcome. ${ }^{2}$

171 High dose cefotaxime regimens $(200 \mathrm{mg} / \mathrm{kg})$ used in adults during pneumococcal meningitis lead to 172 elevated CSF levels associated with satisfying PK-PD parameters in CSF. Despite its limitations this 173 study brings reassuring pharmacological and clinical data regarding the use of high dose cefotaxime as 174 recommended in France for treating pneumococcal meningitis with 3GC susceptible strains.

\section{Authors' contributions}

176 Paul Le Turnier (Conceptualization, Methodology, Investigation, Data curation, Formal analysis, 177 Visualization, Methodology, Writing - original draft), Najoua El Helali (Investigation, Writing - review 178 and editing), Romain Guilhaumou (investigation), Benoit Pilmis (Investigation, Writing - review and 179 editing), Lionel Jean Velly (Investigation) Matthieu Revest (Investigation), Anne Gaelle Leroy 180 (Methodology, Writing - original draft), Xavier Duval (Conceptualization, Investigation, Writing 181 review and editing), Florian Lemaitre (Investigation, Writing - review and editing), Matthieu Grégoire 182 (Conceptualization, Methodology, Investigation, Formal analysis, Visualization, Writing - original draft).

\section{Acknowledgements}

184 Preliminary results of this study were presented as a poster at the 30th European Congress of Clinical 185 Microbiology and Infectious Diseases, Paris, France, 2020 (Abstract 9506). We thank the clinicians, 186 pharmacologists and microbiologists who contributed to the management of the study patients for their 187 commitment to providing optimal patient care. 
DIFCEFO study group: (Nantes University Hospital) Paul Le Turnier, Matthieu Gregoire, Anne-Gaëlle Leroy; (Saint-Joseph group) Najoua El-Helali, Benoît Pilmis; (Rennes University Hospital) Matthieu Revest, Florian Lemaitre; (Marseille University Hospital) Romain Guilhaumou, Lionel Velly (Quimper Hospital) Jean-Philippe Talarmin; (Amiens University Hospital) Jean-Luc Schmit, Youssef Bennis;

192 (Nancy University Hospital) Alexandre Charmillon, Julien Scala-Bertola; (Strasbourg University 193 Hospital) Joy Mootien; (Cochin University Hospital) Solen Kernéis; (Reims University Hospital) Firouze 194 Bani-Sadr, Yohan Nguyen, Zoubir Djerada; (IAME, INSERM, Paris; COMBAT cohort) Xavier Duval.

\section{Funding}

196 The COMBAT cohort study was supported by the Assistance Publique Hopitaux de Paris, French 197 Ministry of Health, Inserm, SPILF, and the Pfizer Pharmaceutical company, which also funded ORP. This 198 ancillary study was carried out as part of our routine work.

\section{Transparency declarations}

None to declare

\section{References}

1. Tubiana S, Varon E, Biron C, et al. Community-acquired bacterial meningitis in adults: in-hospital prognosis, long-term disability and determinants of outcome in a multicentre prospective cohort. Clin Microbiol Infect Off Publ Eur Soc Clin Microbiol Infect Dis 2020; 26: 1192-200.

2. Hoen B, Varon E, de Debroucker T, et al. Management of acute community-acquired bacterial meningitis (excluding newborns). Long version with arguments. Med Mal Infect 2019; 49: 405-41.

207 3. Tunkel AR, Hasbun R, Bhimraj A, et al. 2017 Infectious Diseases Society of America's Clinical 208 Practice Guidelines for Healthcare-Associated Ventriculitis and Meningitis. Clin Infect Dis 2017; 64: 209 e34-65.

210 4. van de Beek D, Cabellos C, Dzupova O, et al. ESCMID guideline: diagnosis and treatment of acute 211 bacterial meningitis. Clin Microbiol Infect 2016; 22: S37-62.

212 5. Kaur R, Pham M, Yu KOA, et al.. Rising Pneumococcal Antibiotic Resistance in the Post-13-Valent 213 Pneumococcal Conjugate Vaccine Era in Pediatric Isolates From a Primary Care Setting. Clin Infect Dis 214 2021; 72:797-805. 
6. Gustafsson I, Löwdin E, Odenholt I, et al. Pharmacokinetic and pharmacodynamic parameters for antimicrobial effects of cefotaxime and amoxicillin in an in vitro kinetic model. Antimicrob Agents Chemother 2001; 45: 2436-40.

7. Doit C, Barre J, Cohen R, et al. Bactericidal activity against intermediately cephalosporin-resistant Streptococcus pneumoniae in cerebrospinal fluid of children with bacterial meningitis treated with high doses of cefotaxime and vancomycin. Antimicrob Agents Chemother 1997; 41: 2050-2.

8. Goldwater PN. Cefotaxime and ceftriaxone cerebrospinal fluid levels during treatment of bacterial meningitis in children. Int J Antimicrob Agents 2005; 26: 408-11.

9. Dahyot-Fizelier C, Frasca D, Grégoire N, et al. Microdialysis Study of Cefotaxime Cerebral Distribution in Patients with Acute Brain Injury. Antimicrob Agents Chemother 2013; 57: 2738-42.

10. Mizrahi A, Marvaud JC, Pilmis B, et al. Emergence of Ceftriaxone Resistance during a Case of Pneumococcal Meningitis with Fatal Evolution. Antimicrob Agents Chemother 2019; 64: e01958-19, /aac/64/3/AAC.01958-19.atom.

11. Hasbun R. Case Commentary: Delayed Cerebral Vasculitis Associated with the Development of Ceftriaxone-Resistant Pneumococcal Meningitis. Antimicrob Agents Chemother 2020; 64: e2251-19, /aac/64/3/AAC.02251-19.atom.

12. Täuber MG, Doroshow CA, Hackbarth CJ, et al. Antibacterial activity of beta-lactam antibiotics in experimental meningitis due to Streptococcus pneumoniae. J Infect Dis 1984; 149: 568-74.

13. Varon 2018. Rapport annuel d'activité du Centre National de Référence des Pneumocoques - Année d'exercice 2017. https://cnr-pneumo.com/docman/rapports/39-2018-epidemiologie-2017/file.

14. Humbert G, Leroy A, Nair SR, et al. Concentrations of cefotaxime and the desacetyl metabolite in serum and CSF of patients with meningitis. J Antimicrob Chemother 1984; 13: 487-94.

15. Peretti P, Sueri L, Tosi M, et al. Cefotaxime in the cerebrospinal fluid and serum in patients with purulent meningitis. J Antimicrob Chemother 1984; 14: 117-23.

16. Le Turnier P, Navas D, Garot D, et al. Tolerability of high-dose ceftriaxone in CNS infections: a prospective multicentre cohort study. J Antimicrob Chemother 2019; 74: 1078-85. 
244 Table 1: Description of study population's characteristics and outcomes, antibiotic therapy

245 characteristics, CSF parameters and pharmacological results ( $\mathbf{n = 3 1}$ patients)

\section{Study population characteristics}

Age, years, median (IQR)

$61(52 ; 69)$

Weight, Kg, median (IQR) ${ }^{\mathrm{a}}$

$75.5(60.7 ; 90.2)$

Glomerular filtration (CKD-EPI) at each CSF

$91(78 ; 105.3)$

samples, $\mathrm{mL} / \mathrm{min} / 1.73 \mathrm{~m}^{2}$, median (IQR) ${ }^{\mathrm{b}}$

Dexamethasone, $\mathrm{n}(\%)$

In-hospital mortality, n (\%)

S. pneumoniae MIC, mg/L, median

$0.25(0.008 ; 0.032 ; 0.5 ; 1)$

$(\min ; \mathrm{Q} 1 ; \mathrm{Q} 3 ; \max )^{\mathrm{c}}$

\section{Characteristics of the cefotaxime therapy}

Daily dosage, g, median (IQR) ${ }^{\mathrm{d}}$

$15(12 ; 19)$

Daily dosage, $\mathrm{mg} / \mathrm{Kg}$, median (IQR)

$200(150 ; 280)$

Continuous infusion, $\mathrm{n}(\%)^{\mathrm{f}}$

$16(57)$

Frequency in intermittent infusion, n/24h, median

$6(4 ; 6)$

(IQR)

Discontinuation for toxicity, $\mathrm{n}(\%)^{\mathrm{g}}$

\section{CSF parameters in samples used for pharmacological}

\section{measurements}


CSF sampling via LP, n (\%)

White blood cells $/ \mathrm{mm}^{3}$, median (IQR) ${ }^{\mathrm{h}}$

Protein g/L, median (IQR) ${ }^{\mathrm{i}}$

Glucose mmol/L, median $(\mathrm{IQR})^{\mathrm{j}}$
$33(75)$

$111(32 ; 565)$

$2.2(1.2 ; 2.7)$

$3.28(1.65 ; 6.11)$

\section{Pharmacological results of cefotaxime measurements}

CSF concentration, $\mathrm{mg} / \mathrm{L}$, median

(min;Q1;Q3;max)

- $\quad$ All patients $(n=44)$

$10.5(1.2 ; 4.9 ; 19.3 ; 43.4)$

- Patients with dexamethasone $(n=33)$

$9.3(1.6 ; 4.5 ; 15.4 ; 39.1)$

- Patients without dexamethasone $(n=11)$

$12.3(1.2 ; 6.5 ; 20.4 ; 43.4)$

Plasma concentration, $\mathrm{mg} / \mathrm{L}$, median

$60.5(13.5 ; 31 ; 81.7 ; 254.9)$

$(\min ; \mathrm{Q} 1 ; \mathrm{Q} 3 ; \max )^{\mathrm{k}}$

$\mathrm{CSF} /$ Plasma concentration ratio, $\%$, median

$21.6(1.4 ; 8.6 ; 28.5 ; 183.8)$ $(\min ; \mathrm{Q} 1 ; \mathrm{Q} 3 ; \max )^{\mathrm{k}}$

CSF/MIC ratio, median (min;Q1;Q3; max $)^{1}$

$38(4 ; 12 ; 146 ; 1844)$

$\mathrm{CSF} / \mathrm{MIC}>10, \mathrm{n}(\%)^{1}$

$25(81)$

246 CTX, Cefotaxime; CKD-EPI, Chronic Kidney Disease EPIdemiology collaboration, LP, Lumbar

247 puncture; PK-PD, Pharmacokinetics-pharmacodynamics; min, minimum; Q1, first quartile; Q3, third

248 quartile; max, maximum.

$249{ }^{a}$ missing data: $\mathrm{n}=3 / 31 ;{ }^{\mathrm{b}}$ creatinin clearance values were collected for each CSF sample, missing data:

$250 \mathrm{n}=4 / 44 ;{ }^{\mathrm{c}}$ missing data: $\mathrm{n}=9 / 31 ;{ }^{\mathrm{d}}$ missing data: $\mathrm{n}=1 / 44 ;{ }^{\mathrm{e}}$ missing data: $\mathrm{n}=4 / 44 ;{ }^{\mathrm{f}}$ missing data: $\mathrm{n}=3 / 31$;

$251{ }^{\mathrm{g}}$ missing data: $\mathrm{n}=6 / 31 ;{ }^{\mathrm{h}}$ missing data: $\mathrm{n}=11 / 44 ;{ }^{\mathrm{i}}$ missing data: $\mathrm{n}=12 / 44 ;{ }^{\mathrm{j}}$ missing data: $\mathrm{n}=13 / 44 ;{ }^{\mathrm{k}}$ missing

252 data: $\mathrm{n}=17 / 44 ;{ }^{1}$ missing data: $\mathrm{n}=14 / 44$. 
253 Table 2. CSF concentrations of cefotaxime according to weight-based daily dosage (n=40 dosages, 4

254 missing data)

\begin{tabular}{|c|c|c|c|c|}
\hline Daily dosage (mg/kg/day) & $<150$ & [150-199] & [200-280] & $>280$ \\
\hline Number of patients & 6 & 6 & 11 & 6 \\
\hline Number of dosages & 9 & 8 & 13 & 10 \\
\hline Time since CTX initiation, hours, & 120 & 144 & 96 & 193 \\
\hline \multicolumn{5}{|l|}{ median } \\
\hline Creatinin clearance, $\mathrm{ml} / \mathrm{min}$, & 51 & 77.5 & 86.0 & 96.5 \\
\hline \multicolumn{5}{|l|}{ median } \\
\hline Creatinin clearance $<30 \mathrm{ml} / \mathrm{min}$, & $4(1 \mathrm{md})$ & 0 & $1(2 \mathrm{md})$ & 0 \\
\hline \multicolumn{5}{|l|}{$\mathrm{n}$} \\
\hline CSF concentration, $\mathrm{mg} / \mathrm{L}$, median & $7.5(1.2 ; 29.3)$ & 10.3 & $5.4(1.6 ; 23.8)$ & 18.3 \\
\hline (range) & & $(2.2 ; 15.4)$ & & $(3.0 ; 43.4)$ \\
\hline
\end{tabular}

255 Md, missing data; CTX, Cefotaxime 